\title{
Investigating the Taste, Odor and Appearance of Selected Bottled and Sachet Sold Drinking Water in Burkina Faso
}

\author{
Michelline Marie Regina Kansole ${ }^{1,}$, Mohamed Beidari² \\ ${ }^{1}$ Engineering School of Fada, University of Fada N'Gourma, Fada N'Gourma, Burkina Faso \\ ${ }^{2}$ Department of Physics, Engineering University of Ouagadougou, Ouagadougou, Burkina Faso
}

\section{Email address:}

dieutrinity@hotmail.fr (M. M. R. Kansole), lebedaroriginal@yahoo.fr (M. Beidari)

${ }^{*}$ Corresponding author

\section{To cite this article:}

Michelline Marie Regina Kansole, Mohamed Beidari. Investigating the Taste, Odor and Appearance of Selected Bottled and Sachet Sold Drinking Water in Burkina Faso. Journal of Water Resources and Ocean Science. Vol. 9, No. 1, 2020, pp. 1-4.

doi: 10.11648 j.wros.20200901.11

Received: December 11, 2019; Accepted: December 21, 2019; Published: January 4, 2020

\begin{abstract}
Background: Drinking water should be harmless to its consumers and aspects such as appearance, taste and/or odor should be acceptable. In Burkina Faso, the sold bottled and sachet drinking waters are not always respecting the quality in terms of potability. Method: In this study we investigated the appearance, taste and/or odor of eleven (11) selected bottled and sachet waters sold in Burkina Faso through a set of five (05) water treatment professionals with ten (10) organoleptic parameters been considered (Organic Solvent, Metallic, Chlorine, Fishy, Sulfur, Earthy, Bitter, Fruity, Spoiled, and Sour). Results: The study showed that all the investigated waters have unpleasant taste and/or odor, with the worst cases in all five (05) brands sachet waters. The bad quality of the sachet waters is generally due to the conditioning (sun, dust, rain). Ouagadougou tap water showed unpleasant chlorine odor mainly caused by the "remanent" chlorine. However, that chlorine ensure the water safety to its consumers. Conclusion: This study showed that the best way to drink safe water in Burkina Faso is to supply a good quality tap water to its population, and to improve the taste and/or odor. Since the sold bottled and sachet waters are not yet well regulated in terms of their quality, the country should be aware of the current study in order to improve the sold drinking water quality.
\end{abstract}

Keywords: Burkina Faso, Bottled Water, Sachet Water, Tap Water, Organoleptic

\section{Introduction}

Drinking water is regulated and intended mainly for human [1]. Thus, it should be out of any type of harmful components, odor and/or taste. While the Environmental Protection Agency (EPA) controls the quality of drinking water in countries like the USA [2], Burkina Faso seems to let it go and the drinking water needs simply to follow some physicochemical trends in order to be acceptable.

In Burkina Faso, the public tap drinking water is produced and distributed by ONEA (Office National de l'Eau et de l'Assainissement). The main parameters considered for the water distribution regarding its potability are the microbiological and physicochemical contents, with sometimes the water appearance [3].

Thus, Taste and/or odor, which are known as organoleptic parameters of the drinking water are not important and until now, they are not considered in the public water treatment plant. In 2017, the population of Ouagadougou had a very strong unpleasant odor in their tap water, leading the majority of them to doubt the quality of their tap water [4]. This scenario discredited the public water treatment company.

However, after investigations, the ONEA could not tell the reasons for this occurred odor, and the same scenario could repeat itself with the same impact since nothing was done to solve the preceding one.

Taste and odor are usually due to the presence of environmental pollutants, chemicals and/or some microalgae products (geosmin and 2-methylisoborneol), and the odor can be detected at very low concentrations less than $1 \mathrm{ng} / \mathrm{L} \ldots$ [57].

Burkina Faso is a poor country that struggles to meet the requirements for drinking water in terms of quantity and quality for its tap water [3]. Thus, many Small and Medium Industries (SMI) are taking advantage of the situation, and 
produce bottled and/or sachet water for selling purpose, with more than two hundreds water selling industries existing in the country. Among those, only fifty-six (56) are been controlled by the public laboratory LNSP (Laboratoire National de Santé publique) [8].

Sachet water is a low-cost way of selling drinking water in poor countries like Burkina Faso [9].

The aim of this article is to investigate the appearance, taste and odor of 11 sold bottled and sachet waters, including the tap water distributed in Ouagadougou (Burkina Faso).

\section{Materials and Methods}

\subsection{The Water Sampling}

Determining the drinking water appearance, taste and/or odor needs methods, which all rely on subjective point of views, with limitation of the tasters [7].

11 Bottled and sachet water were collected. All samples are known to be safe for drinking according to the Laboratoire National de Santé Publique (LNSP) [10].

\subsection{The Water Tasters}

Water tasters were all professional chemical engineers from the national water treatment plant of Burkina Faso (ONEA), and they were coming from the two main water treatment plants of the whole country (Ouagadougou and Bobo-Dioulasso). They were five professionals (two women and three men).

\subsection{Tasting Test Methods}

We used an adapted tasting method A1 described by the UK Environment Agency [7] in 2014 where the samples are looked, tasted and smelled by individuals with immediate notation to see the appearance, taste and/or odor of the water samples. All samples were kept under $5^{\circ} \mathrm{C}$ and were tested at room temperature $\left(27^{\circ} \mathrm{C}\right)$.

To method A1, we combined an adapted tasting procedure described by the Japan Sake and Shochu Makers Association [11].

\subsection{Procedure}

The tasting involved the followings:

i. Pour $20 \mathrm{~mL}$ of the sample in a glassware and observe the appearance

ii. Shake gently the sample for 5 seconds and smell

iii. Rinse the mouth with $10 \mathrm{~mL}$ of deionized water

iv. Taste the sample and spit out the water, do not swallow.

The taste and/or odor investigated were as following: no odor, no taste, organic solvent, metallic, chlorine, sulfur, fishy, earthy, bitter, fruity, spoiled and sour. The clarity of the water was utilized to observe the water appearance and two items were used for the evaluation: 'yes' and 'no' answers.

\section{Results and Discussion}

Figure 1 shows that in the commercialized bottled and sachet waters taste and/or odor are found in both bottled and sachet with predominance in sachet waters.

The presence of chlorine in the tap water is for the safety of the water after it has been treated, and the "remanent" chlorine causes it. However, the concentration found in ouagadougou's tap water is very high, and this is the reason why the smell was detected by all the panelists.

Odors and/or tastes like organic solvent, sulfur, fishy, bitter, earthy, fruity are synonyms of an unsafe and risky drinking water; the quality of such water is not good for consumption. Figure 1 shows that the sachet water have such tastes and/or odors. In fact, sachet waters cost $25 \mathrm{XOF}$ ( $\square 0.04$ USD) for $33 \mathrm{cL}$, and the majority of the population that is very poor can easily afford such amount to quench their thirst [12].

The low cost of sachet drinking waters leads the producers to use (or not) very bad ways to treat properly the water before packaging and sending it to the market place. The majority of the producers use the UV light that is not utilized in a good way and the water packaging is done manually without hygienic conditions sometimes. In addition, only $28 \%$ of the commercialized sachet waters have the authorization of the LNSP for selling [8]. The remaining $72 \%$ are selling without authorization, and their water quality is until now not known.

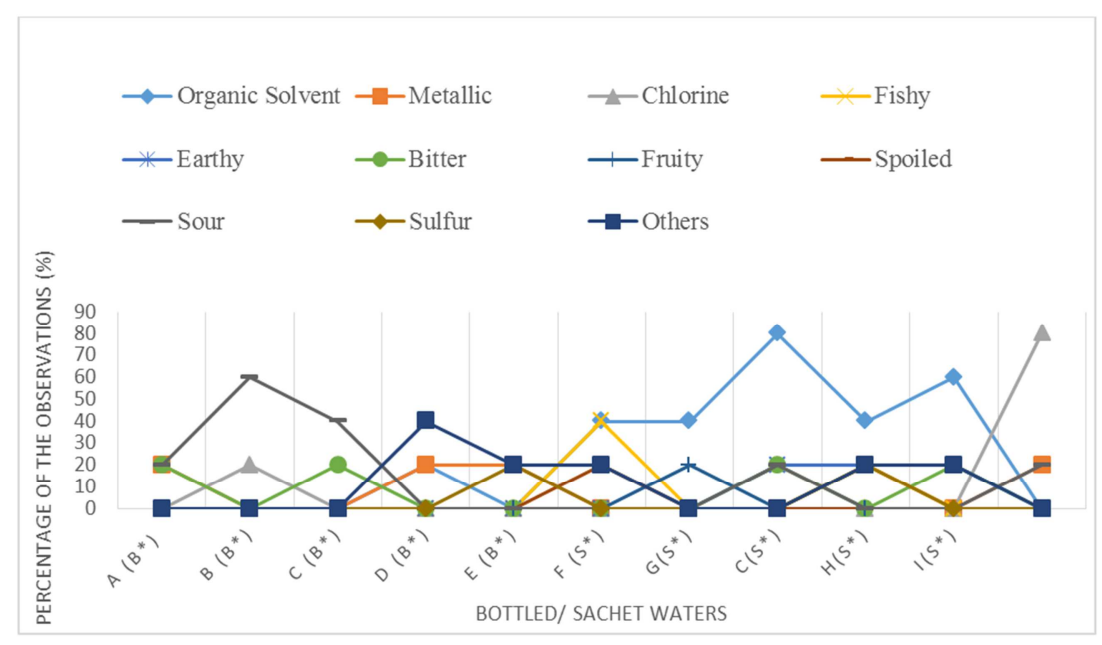

Figure 1. The different tastes and/or odors observed in the selected bottled/sachet waters. 
In Figure 2, the bottled and sachet water look interesting. No tested waters showed any turbidity except for the tap water. For the latest one, the presence of turbidity detected by $20 \%$ of the panelists could be easily explained by the presence of metals in the water, previously observed in Figure 1. Another reason for that appearance may be that the quality of the conduits used to distribute the water is not good (due to corrosion). Thus, more studies need to be conducted in order to know the quality of the tap water along with the distributing pipes systems.

The scenario of 2017 [4], discredited the national public water treatment company ONEA, leading many people to go for bottled waters because they know that the sachet waters have bad conditioning (under sun, dust, rain, dirt) [8].

Chemically, when the sachet, which are made of polyethylene terephthalate (PET) material, is in contact with heat (sun), it releases chemicals that are harmful for human after consumption.

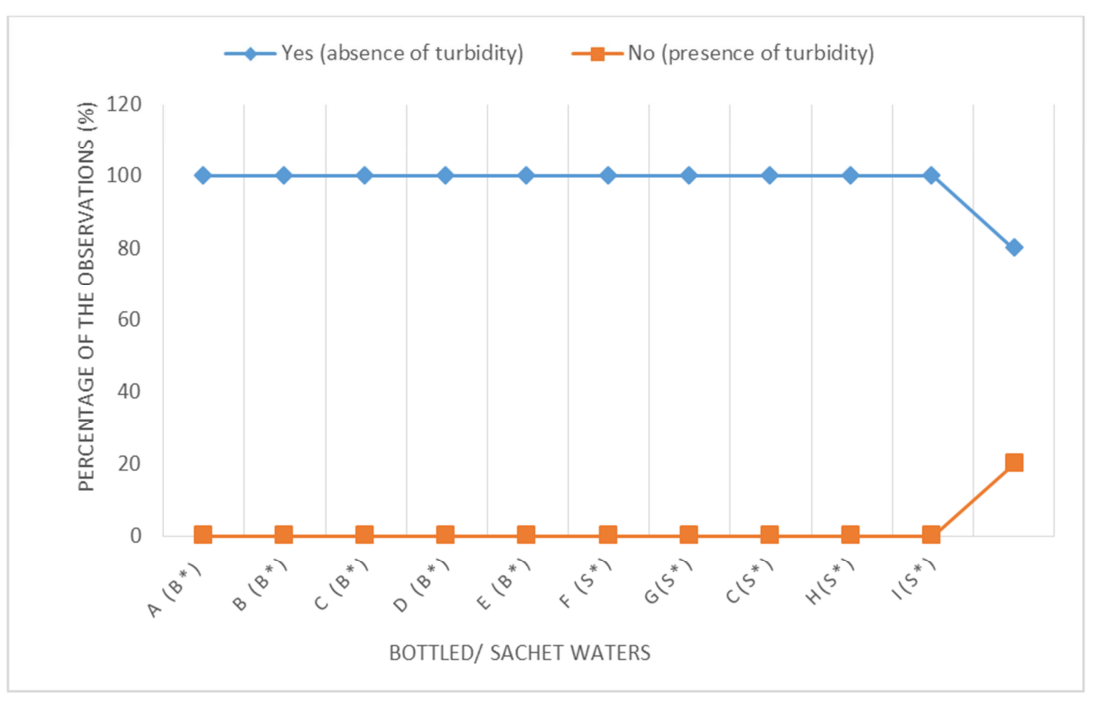

Figure 1. Observations in the selected bottled/sachet waters for their appearance.

In their study, Onuorah et al. [13] found in sachet waters sold in Nigeria, harmful microorganisms such as Staphylococcus aureus and Escherichia coli from 46.67\% and $66.67 \%$, respectively in the studied sachet water brands. The sachet waters should be well checked before they get into the market. The sachet water is safe during the first week of its production, but after that time, it is contaminated by coliforms and becomes unsafe for drinking [14].

In Burkina Faso, more than half of the population has no clean water, and aspects like tastes, odors and/or appearance are put at a second stage, and these parameters are only considered by another category of people in the society. The sachet water is preferred to the tap water because of the chlorine odor, which is unpleasant to consumers, and because of its availability. These reasons lead the majority of the population of Ouagadougou to prefer the sachet water.

However, in terms of safety, the tap water, because of the presence of free chlorine, remains the safest water for human consumption.

From Figure 2, we can easily see that the clarity of the drinking water is what matters more for people as a sign of its potability. What the eye sees tells more than what the taste and/or odor give. This is one of the mindset of the Burkinabe people, leading them to accept drinking waters with unpleasant taste and/or odor. Nevertheless, potable water should be acceptable in terms of its appearance, taste and/or odor [15], and the LNSP should consider these organoleptic aspects in their water quality analysis in order to fit in the guidelines of drinking water established by the World Health Organization (WHO) [15].

\section{Conclusions}

The study we conducted showed that the bottled and sachet waters sold in Burkina Faso do not meet entirely the guidelines of drinking water set by the WHO in terms of organoleptic considerations. The worst case is found in the sachet waters that are somehow unsafe for drinking because of the way they are produced and conditioned.

Despite the fact that Burkina Faso is a poor country, the quality of its drinking water should be tightly analyzed before it is sent to the market place. Water selling industries are very money minded and the public institutions have to take seriously the health of the population that is more or less ignorant in terms of drinking water quality and potability parameters.

Many studies on sachet waters have been conducted in many developing countries, showing the bad quality of the sachet waters, and the current study is a plus to help the population.

In addition, environment is been polluted by the bottles and sachet used to sell the water, and they are not recycled. This is leading to another problem that is the environment pollution. Thus, the solution could simply be to motivate the population to consume and accept the tap water, but they should be supplied a tap water of good quality and 
potability.

Conclusions drawn from the results lead the authors to suggest few recommendations to improve the drinking water quality in Burkina Faso:

i. Ensure strong regulations of the drinking water sector to avoid social and environmental risks;

ii. Implement a customer service to follow the sold drinking water quality; and

iii. Run frequent technical surveys on sold drinking water quality in laboratories.

\section{Acknowledgements}

This study was supported by the University of Fada N'Gourma and the Engineering University of Ouagadougou.

\section{Author Contributions}

Michelline Marie Regina Kansole conducted the research and prepared the manuscript; Mohamed Beidari contributed to preparing the manuscript. Both authors approved the article.

\section{Conflicts of Interest}

The authors have no conflicts of interest to declare.

\section{References}

[1] Parag Y, Tamar. O: Bottled Drinking Water: A Review. Water and Health 2011

[2] US-EPA: Manual of Laboratory Analytical Procedures. Ohio EPA-DES 1997, 1.

[3] Somé TI, Sanda Z, Guilleret JR, Koudogbo B: La qualité de l'eau de distribution dans la ville de Ouagadougou: suivi des paramètres physicochimiques de septembre à janvier 1999 . Sciences et techniques 2002, 25 (12): 105.
[4] Radio Oméga: L'ONEA rassure les populations sur la qualité de l'eau. In: Société. 17 Nov 2017.

[5] Suffet IM, Khiari. D, Bruchet. A: The drinking water taste and odor wheel for the millennium: Beyond geosmin and 2methylisoborneol.. Water Sci Technol 1999, 40: 1-13.

[6] Bruchet A: Drinking Water Materials and Water Organoleptic. Quality: Influence of Plastic Pipes and Synthetic Coatings. CIRSEE, Le Pecq, France 2001.

[7] UK Environment Agency: The Determination of Taste and Odour in Drinking Water; 2014.

[8] Radar Info Burkina: Prolifération de l'eau en sachets: quand l'eau qui donne la vie accélère le pas vers la mort. In: Société. 2019.

[9] Stoler J: Spatial Patterns of Water Insecurity in a developing City: Lessons from Accra, Ghana. PhD. San Diego State University; 2012.

[10] Le faso. net: Laboratoire National de Santé publique (LNSP): voici la liste complète des producteurs d'eau en aout 2018. In: Communiqué 2018.

[11] Japan Sake and Shochu Makers Association: A comprehensive guide to Japan Sake, 1st edn. Japan: Japan Sake and Shochu Makers Association; 2011.

[12] Newborne P, Tucker. J: The urban-rural water interface: A preliminary study in Burkina Faso. In.: Pathways to Resilience in Semi-arid Economies (PRISE); 2015.

[13] Onuorah. S, Odibo. F, Orji. M: An Assessment of the Bacteriological Quality of Commercial Sachet Packaged Water Brands in Awka, Anambra State, Nigeria. Natural Resources and Conservation 2017, 5 (1): 13-20.

[14] Ojekunle. Z O, Ojekunle. V O, Eruola. A O, Oyebanji. F. F, Olatunde. K A, Amujo B, T, Sangowusi O, R, Adekitan. A A, Taiwo. A G: The Effects of Storage on Sachet Water Quality in Ogun State, Nigeria. J Appl Sci Environ Manage 2015, 19 (2): 183-189.

[15] Guidelines for drinking water quality: 10 acceptability aspects: taste, odour and appearance, 4th edn. Geneva: World Health Organization; 2017. 